\title{
Overview of Methodology for Developing Expert System Based on Expert View for Quality of Urban Bus Services in Peninsular Malaysia
}

Shuhairy Norhisham, Muhammad Fadhlullah Abu Bakar, Nor Najwa Irina Mohd Azlan, Siti Nor Dania llyane Yasir Apandi, Nor Hazwani Nor Khalid

To Link this Article: http://dx.doi.org/10.6007/IJARBSS/v11-i12/11829 DOI:10.6007/IJARBSS/v11-i12/11829

Received: 08 October 2021, Revised: 10 November 2021, Accepted: 28 November 2021

Published Online: 12 December 2021

In-Text Citation: (Norhisham et al., 2021)

To Cite this Article: Norhisham, S., Bakar, M. F. A., Azlan, N. N. I. M., Apandi, S. N. D. I. Y., \& Khalid, N. H. N. (2021). Overview of Methodology for Developing Expert System Based on Expert View for Quality of Urban Bus Services in Peninsular Malaysia. International Journal of Academic Research in Business and Social Sciences, 11(12), 910-918.

\section{Copyright: (c) 2021 The Author(s)}

Published by Human Resource Management Academic Research Society (www.hrmars.com) This article is published under the Creative Commons Attribution (CC BY 4.0) license. Anyone may reproduce, distribute, translate and create derivative works of this article (for both commercial and non0-commercial purposes), subject to full attribution to the original publication and authors. The full terms of this license may be seen at: http://creativecommons.org/licences/by/4.0/legalcode

$$
\text { Vol. 11, No. 12, 2021, Pg. } 910-918
$$




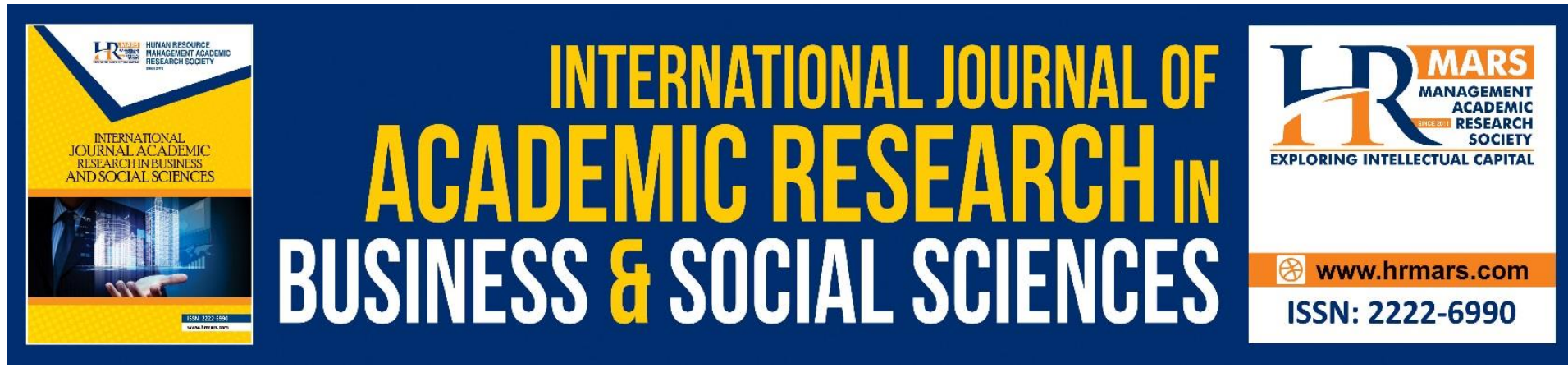

\title{
Overview of Methodology for Developing Expert System Based on Expert View for Quality of Urban Bus Services in Peninsular Malaysia
}

\author{
Shuhairy Norhisham ${ }^{1,2}$, Muhammad Fadhlullah Abu Bakar ${ }^{1}$, Nor \\ Najwa Irina Mohd Azlan ${ }^{1}$, Siti Nor Dania llyane Yasir Apandi ${ }^{1}$, \\ Nor Hazwani Nor Khalid ${ }^{1,2}$ \\ ${ }^{1}$ College of Engineering, Universiti Tenaga Nasional, 43000 Kajang, Selangor, Malaysia, \\ ${ }^{2}$ Institute of Energy Infrastructures (IEI), Universiti Tenaga Nasional, 43000 Kajang, Selangor, \\ Malaysia.
}

\section{Abstract}

Every country in the world have faced a tremendous growth of development over the last decade. The number migrants from rural area to urban area has led to the increasing the traffic volume in urban and cities area. The public transport provided in Malaysia are public buses, taxis, train, Light Rail Transit and so on. Public transport has a very important role towards urban development and at the same time provides convenient transportation to passengers in economic terms. The objective of this study is to review suitable method to development of expert system view for quality of urban bus services in Peninsular Malaysia. The Expert System's knowledge base is the most significant component, as it is selecting rule from the knowledge base and then performs the actions of that rule. After that, the inference engine chooses another rule to execute. As for the framework of this research including task analysis, Data Collection, Development expert system, Refinement, Verification and Evaluation. The framework that on expert system development have been explained in this paper. There are five important attributes for evaluating bus services which are bus frequency, passenger load, Hours of service, on time performance and comparison of travel time of buses and private vehicles. These features were selected based on a as stakeholder questionnaires that conducted by previous research. According to TCQSM, these five attributes are also labelled in the five grades of service quality which are grade $A$ to $E$. There is total 25 questions which is each attribute consists 5 questions each. A complete procedure on the fundamental understanding of the basic notions of the phases of Expert System creation with respect to its methodology and stages of development has been attempted. Keywords: Methodology, Services Quality, Bus Services, Expert System

\section{Introduction}

Every country in the world have faced a tremendous growth of development over the last decade. The number migrants from rural area to urban area has led to the increasing the traffic volume in urban and cities area (Chow \& Bakar, 2019). Public transport is identified as 
the most important sector for the economy as these services also provide a profit return. Profits from public transport revenue can boost the economy of local authorities and communities (Horcher \& Tirachini, 2021). The public transport provided in Malaysia are public buses, taxis, train, Light Rail Transit and so on. Public transport has a very important role towards urban development and at the same time provides convenient transportation to passengers in economic terms. With public transport in place, it can also provide good awareness to foster dependence on private vehicles and reduce carbon dioxide pollution (Boqiang \& Chen, 2020). When most of the middle and high-income people, stay away from public transport, especially buses. As a result, it may affect the decline in the use of public transport in Malaysia. It is further compounded by the increase in the number of private cars.

One of the most important metrics in urban transportation planning is accessibility which quantifies how easy it is to get to a facility (Ribeiro et al., 2021). Public transport provides mobility services to users and it also has an impact on the urban system (Haitao et al., 2019). The difficulty for public transportation authorities (or transit agencies) is to provide a service that is not only efficient and reliable, but also appealing to users (Diab \& El-Geneidy, 2021). Performance measures can be used to better understand the types of transit systems that need to be. Public bus services need to operate efficiently and effectively. The two terms are completely related, and they should be considered as measurements in transit systems.

In Malaysia, public transport is very developed and quite practical, and will save Malaysians from the trouble of dealing with driving. Buses, BRT, light-rail transit (LRT), monorail, express rail link (ERL), and commuter rail make up the present public transportation system (Norhisham et al., 2019). However, the use of public transport especially buses services are decreasing (Deb \& Ahmed, 2018). Therefore, the authorities need to take steps to improve the quality of bus services. Research methods using human experts to calculate the quality of service for bus performance using long manual calculations will be time consuming and costly (Sam et al., 2018). Therefore, expert systems need to be developed because expert system are able to do better work than human experts (Bahadir \& Hatice, 2019). When human experts are unavailable, expert systems are easily accessible. In terms of the time limitation, teaching engineers on an expert system takes significantly less time than training a fresh human expert. Expert systems are less possibility to contain mistakes and the result would be accurate better than manual calculations (Salleh et al., 2015).

Application of expert system could be used on evaluating quality service attributes such as frequency of service, hours of service, punctuality, and passengers load etc. By using this approach, this system could assist and navigate stakeholder, authority and operator in identified the of level of service for bus services especially in urban area (Norhisham et al., 2020). The system must be validated to ensure that it functions properly and that its credibility is maintained at an appropriate level (Bahadir \& Hatice, 2019). The level of bus performance rating is based on consumers' opinion and feedbacks. Perception about terms that not accurate can be used to get the inaccuracies (Munim \& Noor, 2020). By using a decision and organisation system, a knowledgeable engineer verifies the system's performance. Besides, the questionnaire survey to get data and opinion from user (Agyeman \& Cheng, 2020).

The Expert System's knowledge base is the most significant component, as it is selecting rule from the knowledge base and then performs the actions of that rule. After that, the inference engine chooses another rule to execute (Welshi et al., 2015). Expert system give input along the process and at the same time guide the users by providing a few opinions and suggestions for certain problems. Expert systems can become so complex that, without 
accurate and robust techniques, it is not possible to evaluate their performance (Nelms et al., 2020). Through a comparison of the manual computation and the system's results, the operating system has been effectively verified, validated, and evaluated Evaluation also considered as critical part of expert system development consist of three main components known as verification, validation and evaluation the system (Mohammed et al., 2019; Falamarzi et al., 2016). Therefore, the objective of this paper is to review suitable method to development of expert system view for quality of urban bus services in Peninsular Malaysia.

\section{Methodology}

In this section, selection of methodology will explain briefly on developing an expert system for quality of bus service in peninsular Malaysia, interview session as to analysed expert opinion on bus performance rating for quality of service in Malaysia condition and detailing process of evaluation for this system review.

\section{Project Framework}

As for the framework of this research, it requires Task analysis, Data Collection, Development expert system, Refinement, Verification and Evaluation. At this moment, the framework that will be conducted for this research. this development process starting by identify the task analysis to identify the scope and limitation. Next is knowledge acquisition which is the part of data collection. Experts in the relevant subject have been picked to obtain related knowledge in the problem domain. Interviews with professionals in this sector were undertaken in order to obtain the necessary knowledge on risk assessment processes. Experts were contacted by phone and e-mail to set up a meeting to discuss risk assessment techniques. The third phase is development of prototype. In this phase, the tools and software use for this prototype will be chosen. Then, refinement on this project will be done to improve the performance of expert system. Lastly, this project will be evaluated by experts and comparison between manual process and system process will be checked. For developing this expert system, MATLAB are chosen as the preferred expert system framework due to its existence more user-friendly interface.

\section{Task Analysis}

The first step before developing expert system, the developer needs to identify the scope and limitation for this project. The objectives of this project also need to fully understand to achieve the goals. The attributes for bus performance rating to need to be identified A public interview that based on the questionnaire will be conducted with experts such as bus authorities, bus providers and academician. This is important because to gain information about the bus quality service in peninsular Malaysia. This analysis also will identify the time schedule for planning, develop and refinement process period.

Knowledge and Information acquisition

Knowledge and information are acquired through interview with experts. The interview question will be created based on bus performance characteristics. Then, the interview question will be contributed to stakeholders. The interview feedback will be collected for data analysis. 
Prototype System

Software MATLAB was chosen as a tool to build an expert prototype system development in this study. Researchers gain expert knowledge and research release for determine the direction and goals of prototype development. A framework has been planned for the construction of expert systems.

\section{Validation}

Validation is the testing process, and it is the primary means of ensuring that the finished product meets all of the standards. This is the process of examining a system or its component(s) to see whether they meet the specified requirements or not. It is the process of running a system to find any gaps, faults, or missing needs that are not present in the real requirements. This step will test all possible parameters, values, variables and conditions in the input section, as well as check the interface and check the interface flow sequentially.

\section{Evaluation}

A system's evaluation is a procedure that evaluates it critically. It entails gathering and analysing data on the actions, characteristics, and consequences of a programme. Its goal is to make programme evaluations, improve programme effectiveness, and/or guide programming decisions.

\section{Analysis Expert Opinion of Bus Performance Rating for Quality of Service in Malaysia}

In this sub section, interview session was undertaken to experts from related fields namely academician, bus authorities, and bus provider. Data collections are conducted in April 2021.

\section{Interview questions}

There are five important attributes for evaluating bus services which are bus frequency, passenger load, Hours of service, on -time performance and comparison of travel time of buses and private vehicles. These features were selected based on a as stakeholder questionnaires that conducted by previous research. According to TCQSM, these five attributes are also labelled in the five grades of service quality which are grade $A$ to $E$. However, these grades need to be check whether it is accurate and suitable with Malaysia condition. In addition, the opinions of those experts vary according to field, expertise and experience. The probability of providing different solutions at different times was also identified. Therefore, an interview should be conducted with experts to identify if the grade stated by TCQSM is appropriate for Malaysia and identify a consistent solution from the expert group once the service quality grade is identified.

The questions in the interview guideline were derived from current literature. The guideline's questions were designed to be open-ended, with agree or disagree answers expected. There is total 25 questions which is each attribute consists 5 questions each. This question is to check whether the parameter for each level Quality of Service for each attribute is accurate. If experts did not agree with the parameter, then we will take the feedback from the experts to set a new one for each QOS.

\section{Methodology of Interview}

The interviewing session will be undertaken to experts in field and the survey period. This stakeholder will be given interview question through phone call, google teams or email. The 
interview question will be distributed to all experts from transportation field. There are total of 25 questions regarding to quality of service of bus performance rating. The interview questions are divided into 5 attributes and each attribute contain 5 questions. The experts will be asked if they agree with the current parameter of the QOS or they want to set new parameter that suitable with Malaysia condition. Experts can give recommendation or suggestion to improve quality of service in Malaysia. There are total of 20 experts listed and been contacted to set appointment date for interview session. The interview session will be conducted for 10 min until 15 min duration depends on experts. The target respondents are 5 experts from authorities, 5 experts from bus provider, and 5 experts from academician. The minimum experts needed for this study is 10 experts.

\section{Expected Result}

Once the interviews are conducted, the data analysis can be separated to each attribute. Also, improvement proposals have also been sorted according to grade as to isolating and determining the grade of service quality and suggestions for improvement. Other the other hand, the suitability of the grade and should be taken as consideration for new grade according to the expert opinion that will be made for the conditions of urban environment in Peninsular Malaysia. Recorded schedules and suggestions for improvement will be placed along with the grade results in the expert system to be developed.

\section{Methodology of Expert System Development}

In this subsection, the methodology of development of an expert system for quality of bus service divided into four main stages which the first stage consists of the knowledge acquisition. The knowledge base is obtained from a human expert in the second stage, which includes segmentation of the area of interest and extraction of thermally appropriate records the suitability of the grade and will be taken into account for a feature. The inference engine is obtained in the third stage through a statistical analysis of the features and the creation of a decision tree. The user interface is completed in the fourth stage with the validation and feedback of experts. Finally, an expert system is obtained to evaluate quality of bus service in Peninsular Malaysia.

The information and data that obtain from expert through interview session will be used in prototype development. We need to gain expert knowledge and research for prototype development. After the knowledge base is finished, it will be integrated into the expert system so that it can communicate with people. The end user will be able to communicate with the prototype and receive recommendations from the knowledge base via the prototype's user interface. Finally, the user will receive a fix solution from the expert system.

\section{Features in Expert}

There are five attributes available in this expert system for evaluating the quality of bus service in Malaysia. The main user interface which is main menu interface will have the following features; about, e-library, Quality of Service, and exit button. About interface will briefly explain about the expert system to give a clear understanding to user. E-library interface list the definition of every terms used in the expert system and also give short definition for every attribute available in the system. To evaluate bus performance rating for quality of service, the user can choose any attributes available in the QOS interface. In information segment, user need to put engineer name, bus company, bus number, date and 
time. Then, they need to key in all the required data for the attributes to get the result. Lastly, the result showed the Quality of Service for that area and expert suggestion (if available). Next, user can choose whether to continue evaluate other attribute or end the system by click 'Exit' button.

\section{Development of Expert System using MATLAB Software}

Software MATLAB was chosen as a tool to build an expert prototype system development in this study. Researchers gain expert knowledge and research release for determine the direction and goals of prototype development. A framework has been planned for the construction of expert systems. MATLAB has a preferred expert system framework due to its existence more user- friendly interface, as well as can be integrated with other application such as MS Excel. MATLAB is more suitable for completing specific mathematical or technological tasks because this software is a matrix formulation and vectors. Figure 3.5 is an example of a MATLAB main window. MATLAB selected because it is user friendly, and a lot of versatile programming assisted. After the knowledge base is finished, it will be integrated into the expert system so that it can communicate with people. The end user will be able to communicate with the prototype via its user interface and receive recommendations drawn from the knowledge base via the inference engine. Lastly, the user will receive solution from the expert system as a fix solution for decision making.

In prototype development, the design is expected to have evolved according to characteristics selected from options during the knowledge acquisition process. On this stage, the solution element will be wider as well as give values which is better to the system, and a lot of input on information from expert knowledge through interviews can be added. Prototype system once again will be tested to achieve satisfied level. The code and algorithm can be changed to enhance and improve the system process to run smoothly and efficiency. Next, validation is the process of comparing the final result by Bus-ES system and manual calculation. Expert system needs to be testing after the development to make sure that the system run smoothly and perfectly. The manual result from field will be compare with expert system result to check the accuracy of expert system. Result for each attribute will be compared to get the accuracy system.

\section{Methodology of Evaluation of Expert System}

The prototype will be reviewed to ensure that the system functions properly. The major goal of the testing in the evaluation phase is to ensure the system's user-friendliness as well as its reaction time. User friendliness in terms of font used and user interface, simplicity of navigation, and system smoothness are three characteristics that are taken into account. This evaluation is carried out to examine the system's usability, which is regarded a more basic and superficial exam. In this phase, a total of 5 users are involved.

\section{Evaluation}

Last stages known as evaluation process as to ensure the system works correctly without any error. Five characteristics that are focused on is the visibility, real world convention, Error prevention, consistency, and user control. This evaluation is carried out to test the usability of the system which is considered as a simpler and surface testing. A total of 5 users are participating in this phase. Evaluation form will be given to experts listed in table 3.11 to know how well the interface of expert system application is understood. The questionnaires of evaluation were designed using Likert scale values 1 to 5 ( $1=$ Very bad; 2 = bad; $3=$ average; 
4 = good; 5 = Very good). The criteria to evaluate the usability of Expert System application is presented in Table 3.12. Experts fill out the evaluation form in Table 3.12 based on their experience when using the expert system.

At this stage, the user will enter the Bus-ES system and they will read information about the system. Then, they will choose any attributes and enter input of the field data. After they completed all the information needed in the interface, they can select result button to see the output. After that, the users can continue to choose other attribute and do the same step to get the result. Lastly, they could exit the system if they already finished using it. From their experience using the system, they can evaluate how the system work based on 5 values which are: visibility, real world convention, consistency, error prevention and user control.

\section{Conclusion}

As a conclusion, the paper is aimed to develop an overview of methodology for developing expert system based on expert view for quality of urban bus services in Peninsular Malaysia. This method would provide an overview of the processes and methods used in the creation of Expert Systems. A complete procedure on the fundamental understanding of the basic notions of the phases of Expert System creation with respect to its methodology and stages of development has been attempted. The method on developing questionnaire and evaluation on the expert system also explained in this paper as part of the system development. Many researcher and relevant parties have recognised the practical benefits of the experts System as a part of industrial revolution 4.0 process and the technology demand in country future development. Expert system can assist people on accelerating economic growth and solving crucial difficult problems in important sectors can be tackled. Further using the method in this area is highly recommended in future.

\section{Acknowledgement}

The authors gratefully acknowledge use of the service and facilities of the Institute Energy, Universiti Tenaga Nasional and this study is funded by Yayasan Canselor Universiti Tenaga Nasional (202101015YCU).

\section{Corresponding Author}

The corresponding author is Dr. Shuhairy Norhisham, Senior Lecturer at Universiti Tenaga Nasional, Malaysia. Email address: shuhairy@uniten.edu.my, Address: College of Engineering Jalan Ikram - Uniten, 43000, Kajang, Selangor, Malaysia.

\section{References}

Agyeman, S., \& Cheng, L. (2020). Analysis of barriers to perceived service quality in Ghana: Students' perspectives on bus mobility attributes. Transport Policy, 99, 63-85.

Bahadir, M. C., \& Hatice, C. A., (2019). The System Dynamics Modelling for Container Capacity \& Transportation Planning Policies. The Asian Journal of Shipping and Logistics, 35(4), 200-212.

Boqiang, L. \& Chen, Y. (2020). Will land transport infrastructure affect the energy and carbon dioxide emissions performance of China's manufacturing industry? Applied Energy, 260(2020), 1-13.

Chow, M. F., \& Bakar, M. F. A., (2019). Environmental benefits of green roof to the sustainable urban development: A review, Lecturer Notes in Civil Engineering, 9, 1525-1541. 
Deb, S., \& Ahmed. M. A., (2018). Determining the service quality of the city bus service based on users' perceptions and expectations. Travel Behaviour and Society, 12, 1-10.

Diab, E., \& El-Geneidy. A., (2021). Bus Public Transport Planning and Operations, International Encyclopaedia of Transportation, 2021, 326-332.

Falamarzi, A., Rahmat, R. A., Borhan, M. N., Cheragi, S., \& Javadi, H. H. S. (2016). Development of a fuzzy expert system to prioritize traffic calming projects, Jurnal Teknologi, 78(2), 43-53.

Haitao, H., Yang, K., Liang, H., Menendez, M., \& Guler. S. I. (2019). Providing public transport priority in the perimeter of urban networks: A bimodal strategy. Transportation Research Part C: Emerging Technologies, 107, 171-192.

Horcher, D. \& Tirachini, A. (2021). A review of public transport economics. Economics of Transportation, 25(2021), 1-34.

Mohammed, A., Ambak, K., Mosa, A. M., \& Syamsunur, D., (2019). Expert system in engineering transportation: A review, Journal of Engineering Science and Technology, 14(1), $229-252$.

Munim, Z. H., \& Noor, T. (2020). Young people's perceived service quality and environmental performance of hybrid electric bus, Travel Behaviour and Society, 20, 133-143.

Nelms, M. D., Karmaus, A, L., \& Patlewicz, G., (2020). An evaluation of the performance of selected (Q)SARs/expert systems for predicting acute oral toxicity. Computational Toxicology, 16, 1-12.

Norhisham, S., Bakar, M. F. A., Syamsir, A., Zaini, N., Baharin, N. L., Shkuri, N. S. M., \& Saad, N. M. (2020). Development of expert system for bus services in Klang Valley, IOP Conference Series: Earth and Environmental Science, 708(1) doi:10.1088/17551315/708/1/012039 Retrieved from www.scopus.com.

Norhisham, S., Bakar, M. F. A., Tajri, A., Mohamad, D., Yatuka, S., Masjuki, S. A., Shkuri, N. S., \& Zaini, N. (2019). Assessing stakeholder's view for quality bus services in kuala lumpur. International Journal of Advanced Science and Technology, 28(10), 359-369.

Ribeiro, J., Fontes, T., Soares, C., \& Borges. J. L., (2021). Accessibility as an indicator to estimate social exclusion in public transport. Transportation Research Procedia, 52, 740-747.

Sam, E. F., Hamidu, O., \& Daniels, S., (2018). SERVQUAL analysis of public bus transport services in Kumasi metropolis, Ghana: core user perspectives. Case Studies on Transport Policy 6 (1), 25-31.

Salleh, B. S., Atiq, R., Rahmat, O. K., \& Ismail, A., (2015). Expert System on Selection of Mobility Management Strategies towards Implementing Active Transport. Procedia-Social and Behavioral Sciences, 195, 2896 - 2904.

Welshi, L., Aiping, L., Shudong, L., (2015). A method for knowledge acquisition in diagnostic expert system, Technology and Health Care, 23(1), 55 -59. 